\title{
Biotech rallies in Q3
}

\section{Walter Yang}

Biotech stocks stormed back with the rest of the markets last quarter. Although funding for public biotechs was $\$ 9.1$ billion, up 55\% from the same quarter last year, this figure was largely the result of debt deals completed by Amgen, Gilead and Valeant. For the sector as a

\section{Stock market performance}

In the past quarter, biotech indices performed (up 12\%) similarly to the Dow and S\&P 500 (up 10\% and 11\%, respectively).

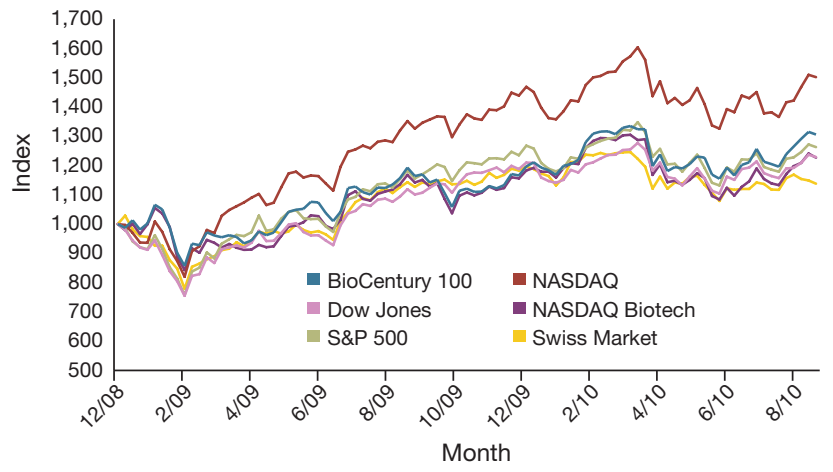

\section{Global biotech industry financing}

Although money raised by public offerings and PIPEs was down $77 \%$ on the same quarter last year, debt financings grew nearly threefold.

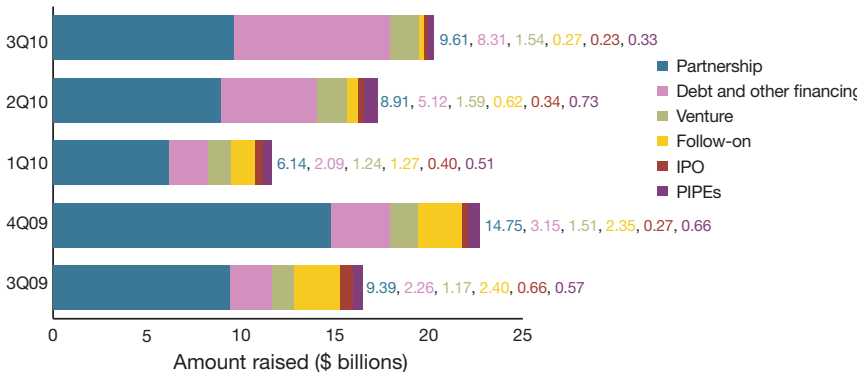

PIPEs, private investment in public equities. Partnership figures are for deals involving a US company. Source: $\mathrm{BCIQ}$ : BioCentury Online Intelligence, Burrill \& Co.

\section{Global biotech initial public offerings}

Money raised from IPOs fell 65\% to $\$ 230.7$ million from 3Q09.

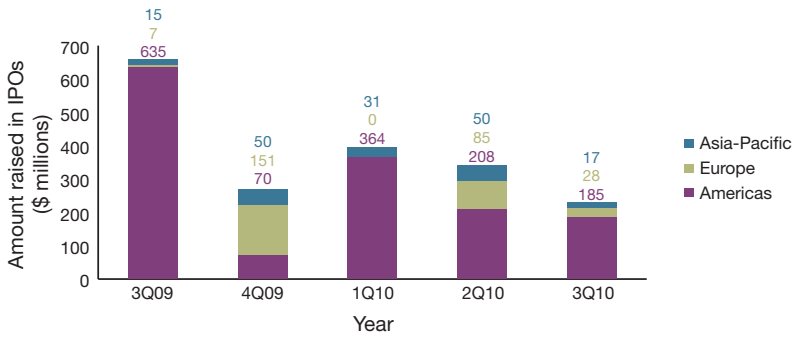

$\begin{array}{lccccc} & 3 \mathbf{Q 0 9} & \mathbf{4 Q 0 9} & \mathbf{1 Q 1 0} & \mathbf{2 Q 1 0} & \mathbf{3 Q 1 0} \\ \text { Americas } & 2 & 2 & 4 & 4 & 3 \\ \text { Europe } & 1 & 2 & 0 & 5 & 1 \\ \text { Asia-Pacific } & 1 & 2 & 2 & 1 & 1\end{array}$

whole, equity financings for public biotechs were the lowest since the depths of the economic meltdown in Q408, when the industry raised only $\$ 270.6$ million. Private financing remains buoyant (above $\$ 1$ billion).

\section{Global biotech venture capital investment}

Venture money raised was up 31\% to $\$ 1.5$ billion from $\$ 1.2$ billion $3 Q 09$.

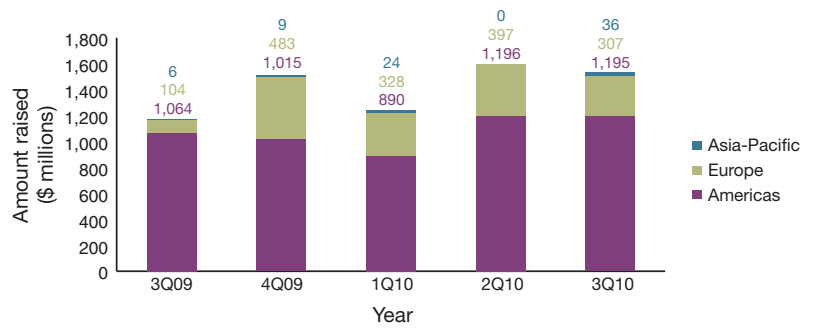

$\begin{array}{lccccc} & \mathbf{3 Q 0 9} & \mathbf{4 Q 0 9} & \mathbf{1 Q 1 0} & \mathbf{2 Q 1 0} & \mathbf{3 Q 1 0} \\ \text { Americas } & 49 & 58 & 58 & 75 & 52 \\ \text { Europe } & 14 & 34 & 30 & 27 & 22 \\ \text { Asia-Pacific } & 1 & 1 & 1 & 1 & 3\end{array}$

Table indicates number of venture capital investments and includes rounds where the amount raised was not disclosed. Source: $\mathrm{BCIQ}$ : BioCentury Online Intelligence

\begin{tabular}{|c|c|c|c|c|c|c|}
\hline \multicolumn{4}{|c|}{ Notable Q3 deals } & \multirow{3}{*}{$\begin{array}{c}\text { Amount } \\
\text { raised } \\
\text { (\$ millions) }\end{array}$} & \multirow[b]{3}{*}{$\begin{array}{l}\text { Round } \\
\text { number }\end{array}$} & \multirow[b]{3}{*}{$\begin{array}{l}\text { Date } \\
\text { closed }\end{array}$} \\
\hline Venture cap & oital & & & & & \\
\hline \multicolumn{4}{|c|}{ Company (lead investors) } & & & \\
\hline \multicolumn{4}{|c|}{ Pacific Biosciences ${ }^{\mathrm{a}}$ (Gen-Probe) } & 109.0 & 6 & 14-Jul \\
\hline \multirow{2}{*}{\multicolumn{4}{|c|}{$\begin{array}{l}\text { Reata (CPMG, Novo A/S) } \\
\text { immatics (MIG Funds, AT Impf, dievini } \\
\text { Hopp BioTech) }\end{array}$}} & 78.0 & 7 & $12-J u l$ \\
\hline & & & & 70.5 & 3 & 21-Sep \\
\hline \multicolumn{4}{|c|}{ Relypsa (OrbiMed) } & 70.0 & 2 & 13-Sep \\
\hline \multicolumn{4}{|c|}{$\begin{array}{l}\text { Cerenis }{ }^{\mathrm{b}} \text { (Fonds Stratégique d' } \\
\text { Investissement) }\end{array}$} & 51.7 & 3 & 26-Jul \\
\hline \multicolumn{4}{|c|}{ Mergers and acquisitions } & & Value & \\
\hline \multicolumn{4}{|l|}{ Target } & Acquirer & (\$ millions) & announced \\
\hline \multicolumn{4}{|l|}{ Talecris } & Grifols & 3,400 & 7-Jun \\
\hline \multicolumn{4}{|l|}{ Crucellc } & $\begin{array}{l}\text { Johnson \& } \\
\text { Johnson }\end{array}$ & 2,200 & 17-Sep \\
\hline \multicolumn{4}{|c|}{ ZymoGenetics } & $\begin{array}{l}\text { Bristol-Myers } \\
\text { Squibb }\end{array}$ & 885 & 7-Sep \\
\hline \multicolumn{4}{|l|}{ Movetis } & Shire & 560 & 3-Aug \\
\hline \multicolumn{4}{|l|}{ IPOs } & & Change & \\
\hline \multicolumn{4}{|c|}{ Company (lead underwriters) } & $\begin{array}{l}\text { raised } \\
\text { (\$ millions) }\end{array}$ & $\begin{array}{c}\text { in stock } \\
\text { price } \\
\text { since offer }\end{array}$ & $\begin{array}{c}\text { Date } \\
\text { completed }\end{array}$ \\
\hline \multicolumn{4}{|c|}{$\begin{array}{l}\text { Amyris (Morgan Stanley, JP Morgan, } \\
\text { Goldman Sachs) }\end{array}$} & 84.8 & $8 \%$ & 28-Sep \\
\hline \multirow{2}{*}{\multicolumn{4}{|c|}{$\begin{array}{l}\text { Seegene } \\
\text { NuPathe (Leerink, Lazard) }\end{array}$}} & 17.5 & $25 \%$ & 13-Sep \\
\hline & & & & 50.0 & $-28 \%$ & 6-Aug \\
\hline \multicolumn{4}{|c|}{ Trius Therapeutics (Citigroup) } & 50.0 & $-21 \%$ & 3-Aug \\
\hline \multicolumn{4}{|c|}{ Novagali Pharma (Bryan, Garnier) } & 28.4 & $3 \%$ & 21-Jul \\
\hline \\
\hline \multicolumn{7}{|c|}{ Value } \\
\hline Arena & Eisai & 1,370 & \multicolumn{4}{|c|}{$\begin{array}{l}\text { Exclusive US rights to market Arena's obesity } \\
\text { compound lorcaserin }\end{array}$} \\
\hline Aileron & Roche & 1,125 & \multicolumn{4}{|c|}{$\begin{array}{l}\text { Discover, develop and commercialize therapeutics } \\
\text { against up to five undisclosed targets using Aileron's } \\
\text { stapled peptide technology }\end{array}$} \\
\hline Orexigen & Takeda & 1,050 & \multicolumn{4}{|c|}{$\begin{array}{l}\text { Exclusive rights to commercialize obesity candidate } \\
\text { Contrave in the US, Canada and Mexico }\end{array}$} \\
\hline $\begin{array}{l}\text { Seattle } \\
\text { Genetics }\end{array}$ & Roche & 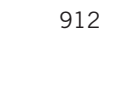 & \multicolumn{4}{|c|}{$\begin{array}{l}\text { Adds antigens to a } 2002 \text { deal that gave Roche unit } \\
\text { Genentech rights to use its antibody-drug conjugate } \\
\text { technology }\end{array}$} \\
\hline
\end{tabular}

Walter Yang is Research Director at BioCentury 